\title{
What Supports Supportive Therapy?
}

Peter N. Novalis, M.D., Ph.D.

Saint Elizabeth's Hospital, Washington DC

Follow this and additional works at: https://jdc.jefferson.edu/jeffjpsychiatry

Part of the Psychiatry Commons

Let us know how access to this document benefits you

\section{Recommended Citation}

Novalis, M.D., Ph.D., Peter N. (1989) "What Supports Supportive Therapy?," Jefferson Journal of Psychiatry. Vol. 7 : Iss. 2 , Article 5.

DOI: https://doi.org/10.29046/JJP.007.2.003

Available at: https://jdc.jefferson.edu/jeffjpsychiatry/vol7/iss2/5

This Article is brought to you for free and open access by the Jefferson Digital Commons. The Jefferson Digital Commons is a service of Thomas Jefferson University's Center for Teaching and Learning (CTL). The Commons is a showcase for Jefferson books and journals, peer-reviewed scholarly publications, unique historical collections from the University archives, and teaching tools. The Jefferson Digital Commons allows researchers and interested readers anywhere in the world to learn about and keep up to date with Jefferson scholarship. This article has been accepted for inclusion in Jefferson Journal of Psychiatry by an authorized administrator of the Jefferson Digital Commons. For more information, please contact: JeffersonDigitalCommons@jefferson.edu. 


\title{
What Supports Supportive Therapy?
}

\author{
Peter N. Novalis, M.D., Ph.D.
}

Think of 1896, the year Jacob Freud died, kindling a depression in his son Sigmund which led to The Interpretation of Dreams. To a raucous convention in Chicago, William Jennings Bryan declaimed against the gold monetary standard: "You shall not press down upon the brow of labor this crown of thorns, you shall not crucify mankind upon a cross of gold" (1). Years later the monetary gold standard was abandoned during the New Deal, but Freud's newly mined "pure gold of analysis" continued to be an object of adulation and emulation, despite Freud's prediction that its exoteric application would require alloys "with the copper of direct suggestion" (2).

One such alloy is supportive psychotherapy. Wallerstein (3) defines it as an ego-strengthening therapy which uses means other than interpretation or insight to help the patient suppress mental conflict and its attendant symptoms. Bloch deems it a form of treatment for patients with "chronic psychiatric conditions for whom basic change is not seen as a realistic goal," and its aim is to sustain a patient who cannot independently manage his or her own life (4). Werman describes it as a substitutive form of treatment, one that supplies the patient with those psychological functions that he or she either lacks entirely or possesses insufficiently (5).

Until recently, however, supportive therapy was like a neglected patient who had been coming to clinic for many years, but never received the courtesy of a psychodynamic formulation. Only in this decade has it been appreciated as a distinct type of therapy with its particular patients, goals, and techniques, defined by its own ground rules and theory of psychopathology. This paper presents the rationale which underlies supportive psychotherapy and the basis on which it constitutes a distinct type of treatment.

\section{THE COMMON ELEMENTS}

It is by now a truism that all forms of therapy involve supportive elements, and that these aspects play a role in the success of therapy (6). We know that Freud fed herring to the Rat Man, and that this feeding, as well as the Rat Man's familiarity with Freud's family, played a role in his cure (7). Both these aspects are viewed as aberrations of what has now become Freudian technique, even though Freud violated it. Kohut also recognized the need for supportive empathy to bolster the self-esteem of $\mathrm{Mr}$. Z, who had failed to improve from a course of more traditional therapy (8).

Although supportive therapy embodies traditions of counseling and advice 
which go back to ancient times, its first clear-cut formulations were made by Alexander and French (9) and by Gill (10). Gill was one of the first to recognize that the usual interpretation of defenses could not be applied to patients with low ego strength, who risked regression and could not handle the anxiety. From this starting point, albeit slowly, the concept of supportive therapy as an ego-building or self-esteem enhancing therapy was elaborated in the ensuing years by Alexander (11), Goldman (12), DeWald (13), and others. More recently, it has been the subject of a major review (14) and an entire issue of Psychiatric Annals $(15,16,17,18)$.

On an alternative track, supportive therapy also became widely used as a technique for counseling "psychologically healthy" patients in crisis (medical illness, disaster, bereavement) as well as "unhealthy" patients in crisis (e.g., a dysthymic patient who attempts suicide). Most therapists have had occasion to shift modes from insight-oriented therapy to supportive therapy at the time of some intercurrent crisis. This use of supportive therapy is continuous with its application as a long-term treatment.

Supportive therapy is often contrasted with psychoanalysis and psychodynamic psychotherapy. Although there are many differences between the latter two, for our purposes we will lump them together as examples of what we shall call psychodynamic therapy. Psychodynamic therapy is a means of uncovering conflict and using interpretation and insight to foster personality change.

There is substantial agreement among practitioners on the general characteristics of the two types of therapies $(14,15,18,19)$. In general, the psychodynamic therapist develops an anonymous, neutral, abstaining relationship with the patient in order to achieve the goals of long-term characterological change, resolution of infantile neurosis, a weakening of dysfunctional defenses and an expansion of ego functions according to Freud's dictum that "where id was, there ego shall be" (20). To those ends, the therapist may encourage free associations and fantasy in the patient and an intense transferential relationship.

By contrast, the supportive therapist fosters a more active and directive relationship, promoting a positive, but limited transference and some degree of dependency. The goals of such therapy are symptom and behavioral control, or restoration and maintenance of the patient's functioning, and it reaches those goals through support of the patient's ego functions and strengthening of adaptive defenses and coping behaviors.

\section{PATIENT SELECTION}

How do patient characteristics govern the choice of therapy? The choice of the best available therapy is based on the patient's ego deficits, motivation, impulse control, and ability to think psychologically. Detailed selection procedures are provided by several authors $(5,13,21)$.

Insight-oriented therapy is felt to be effective in modifying psychopathology and achieving long-term character change in patients with substantial ego 
strength and flexibility. A typical such patient is bothered by a conflict (primarily Oedipal), thinks psychologically, has an observing ego, can maintain a verbal relationship and, in general, has now and has had in the past a supportive environment. He or she can tolerate the stress and anxiety arising from the therapist's interpretation because he or she has good impulse control, contains affect, obtains symptom relief by understanding, and does not act out internal conflicts. For a suitable patient, psychodynamic therapy would produce the most stable and enduring change and would be preferred over supportive therapy. Its success, however, requires the patient to do much of the analytic work himself or herself. He or she will have various tasks, such as working through unresolved childhood conflicts by means of a transference neurosis focused on the therapist. To perform these tasks, the patent must, in general, be cognitively intact, in touch with his or her emotions, and enter the therapy with relatively mature defenses and a reasonable ego structure.

This engenders what Werman (22) calls the "recognized paradox" that psychodynamic therapy gives the most benefit to the most integrated individuals. It leaves out those suffering from schizophrenia, substance abuse, dementia and mental retardation, or in other words the majority of chronic mental patients. Although highly skilled and dedicated analysts have successfully treated severe psychopathology, and no particular diagnosis per se rules out analysis, these chronically ill patients are usually unable to benefit from insight-oriented therapy. They have a low capacity for introspection. They do not psychologize, but act out their unconscious content or exhibit biologically compelled behavior. They cannot contain negative affect, and exhibit poor object relations and impulse control. Their conflicts are pre-Oedipal. Their defenses are primitive and their ego strength is low. They may be cognitively impaired. They are in danger (often imminent) of hurting themselves and others. They have suffered and will continue to suffer unstable relationships. They require the more active and directed relationship of supportive therapy.

\section{THE TECHNIQUES}

Winnicott remarked that "the analysis of a psychotic is irksome as compared with that of a neurotic, and inherently so" (23). Similarly, a therapist trained in interpretive techniques may initially find supportive therapy frustrating. Understanding the patient is often thwarted by personal and social differences from the therapist, who has not experienced the disorganization and deterioration of chronic mental illness and may be unable to relate empathically to its victims.

For these reasons, supportive therapy is actually a considerably more complex undertaking than psychodynamic therapy. It requires the same understanding of the patient's psychopathology, e.g., his or her character structure and defenses, as the therapist strives for in psychodynamic therapy, yet the interventions are of broader range, encompassing, at times, the interpretations of analysis, but also a host of suggestions, gratifications and directives which have 
to be carefully chosen as to timing, wording, and calculated impact. Wallace (24) refers to the debate in the therapist's mind over confronting or supporting a defense, or gratifying a request instead of analyzing it. These questions do not usually arise for the analyst, although they can create a "moral struggle" in the psychodynamic therapist, who may worry that these are deviations in technique. Eissler has called these deviations "parameters" which must be justified and later analyzed away (25). In supportive therapy, however, they may be key components of strategy.

We can divide the techniques of supportive therapy into two kinds. First, there are modifications of psychoanalytic or psychodynamic techniques. Second, there are those techniques that are specifically supportive. Psychoanalytically derived techniques include the formulation and giving of interpretations, the specific fostering of transference, and dream analysis. All have received significant attention in the literature of supportive therapy.

For example, Werman (5) explains how intellectualizing and rationalizing interpretations may be offered to diminish guilt or provide defenses against anxiety. Upward interpretations are used frequently, even of hallucinations. Pine offers four concise rules for speaking interpretively in the supportive context (17). These are, slightly rephrased, as follows:

1. Control or limit the patient's associations to interpretations.

2. Strike while the iron is cold (that is, when the patient's emotions have cooled about the situation interpreted).

3. Involve the patient actively in the interpretation.

4. Increase the "holding" aspects of the therapeutic environment.

These rules seem to be common sense, given the patient's presumed difficulties in tolerating the anxiety that would be evoked by more psychodynamic interpretations. With a similar sensitivity to the patient's ego deficits, Werman has concluded that it is, again, a matter of knowing what not to say, that is, avoiding regressive interpretations in favor of interpreting upwards. $\mathrm{He}$ recounts a schizophrenic patient's dream of beating the neighbor's dog. The therapist interprets the displaced anger as permissible and suggests that the patient will not turn it into action (26). More regressive interpretations (e.g., that the dream refers to masturbation) are to be avoided. The therapist adapts to the patient's ego structure by choosing interpretations based on the patient's readiness to accept or assimilate them. Thus, upward interpretation may be best suited for the patient who cannot tolerate sexual anxiety (e.g., a paranoid patient).

In addition to modified psychoanalytic techniques, there are special techniques which are primarily supportive. These include advice, suggestion, expressions of concern, reassurance, encouragement, teaching, education, and guidance. More elaborate strategies, such as the psychodynamic life narrative (27) and reference to the "good" and "bad" parts of the patient (28), have also been developed. All are employed in the service of improving the patient's reality- 
testing, coping abilities, and impulse control. Regarding the latter, Wallerstein's characterization of supportive therapy as suppressive is especially apt. Werman similarly counsels patients to suppress the thought processes that lead to "unhandleable" anxiety and recommends that patients be taught to rehearse specific intellectual formulations to deal with frightening or depressing situations (5). He considers this technique to be derived from behavior modification, "which in general should be considered in supportive therapy when deemed appropriate"' (22).

Other specifically supportive techniques include the strengthening of defenses (as opposed to their weakening through interpretation) and the use of the therapist as an (uninterpreted) role model or mentor (for example, to show the patient it is not necessary to act immediately on impulses). Both of these examples touch upon how the therapist acts and relates to the patient. Psychoanalytic therapists writing about such techniques have varied in their criteria for admissibility into therapy. Greenson, for example, allows a limited role for abreaction, suggestion, and even manipulation, but condemns the "deliberate and conscious assumption of roles or attitudes" because "it creates an unanalyzable situation" (29). However, an unanalyzable situation in supportive therapy is not intolerable and may be preferable.

Sullivan considers three other techniques from a learning theory perspective (30). These are:

(1) expressions of interest and solicitude,

(2) giving advice, and

(3) ventilation

Though these are included among supportive techniques, he shows how each can be misapplied by misunderstanding the nature of the behavioral conditioning. First, sporadic or random expressions of concern are a strong reward which might have the unintended effect of simply reinforcing the patient's repetitive verbalization of problems without making constructive progress. Second, advice is often eschewed by psychiatrists as overly directive, but may also be effective because it reinforces desired behaviors. Sullivan's simple example of suggesting to the patient that he get a dog, shows how directive advice can be quite specific. Can such advice-giving backfire? Of course, but so can non-directive interventions. Third, ventilation of feeling per se can be dangerous and is in fact often opposed to another technique, control of affect. What is important is ventilation in a supportive setting so as to gain a sense of mastery. As Sullivan notes, the mere ventilation of negative feelings, e.g., in a ward meeting, may reinforce low morale and perpetuate the externalization of blame for the patient's problems.

\section{DANGERS AND OBJECTIONS}

It is obvious that in the supportive relationship there are inherent dangers to both patient and therapist. Dangers to the patient include dependency on the therapist and loss of autonomy. Dangers to the therapist include his or her 
willful or unwitting imposition of values on the patient and the use of the real relationship with the patient for narcissistic gratification, grandiosity, and power, or the misuse of the relationship as a non-therapeutic friendship. The latter is the dynamic which in the extreme can become sexual misconduct.

It is no accident that the "gold standard" of a benign, but non-interfering, therapist is held in most quarters, because it represents the view that more directive interventions are wrong in some sense. Langs, for example, who sanctions the therapist's intervention in cases of acting out or acute regression, goes on to severely limit supportive interventions. His general objections are that they may represent (1) countertransference problems, (2) theoretical misunderstandings, or (3) misguided techniques.

Langs gives a vignette in which the therapist, for various reasons, counseled his character-disordered male patient to stop sharing a bedroom with his mother because of the correct realization that this promoted incestuous fantasies about her which were, in turn, defended against by homosexual fantasies. The repercussions of this apparently well meant and justified advice were manifold (31). The patient believed that the therapist was telling him to give up women and that the therapist wanted him for himself. He was further afraid that the therapist was trying to play God and this frightened the patient because of his dependency on the therapist. Langs generalizes that advice is dangerous for the reasons which are summarized as follows:

1. Advice usually results in mistrust, resistance, and suspicion. It is dangerous to the therapeutic alliance.

2. Advice fosters dependency and submissiveness and infantilizes the patient. A patient's fear of going mad or losing control of his or her impulses is increased by the therapist's implication that he or she needs restraint or direction. Giving advice, therefore, is anxiety-provoking, or else provokes rage at the therapist or desires for revenge.

3. Moreover, it deprives the patient of the opportunity of working out his or her own intrapsychic conflicts, which may actually weaken, not strengthen, the patient's defenses.

4. Advice is viewed as an intrusion on the patient's autonomy, or more primitively, on his or her body, even as a seduction or homosexual assault.

5. Advice is a mode of interference which has been practiced on the patient by his or her family, and may increase negative transference. In addition, it violates the patient's rights.

6. Any advice creates risks, since the therapist's advice is based on incomplete information and could be wrong. "Such a stance," says Langs, "is almost never necessary or justified."

7. If the patient stops one form of acting out on the therapist's advice, he or she will replace it with another. 
The following case vignettes illustrate the complexities of managing a supportive relationship, especially when the therapist has a dual role vis-a-vis the patient (Case 1) or is working with a case manager who has a different role (Cases 2 and 3$)$.

Case 1. A 37-year-old man with a history of schizophrenia and many hospitalizations is seen in weekly therapy. After a year, the therapist feels he has developed sufficient rapport and understanding so that he can more actively direct the improvement of his patient's life. On one occasion the patient asks to be admitted to the hospital, but the therapist, after assessing the situation, counsels him to stay out. Later, the therapist finds out that the patient was actively hallucinating at the time of the request, but did not tell the therapist. The therapist encourages the patient to get his driver's license, to apply for jobs, and to socialize in clubs. One day the patient's mother is hospitalized for an illness, but the patient does not call the therapist despite the urgings of the family. The patient says to his family, "Dr. X won't let me go to the hospital. There's no use in asking." That week the patient dies of an apparent overdose of his antipsychotic medication.

Case 2. A family which has been seen frequently by a case manager for a year is engaged in family therapy. The 22-year-old daughter admits to the new therapist on the second visit that she is heavily into cocaine, but says she won't tell her case manager because the latter thinks too highly of her.

Case 3. A 24-year-old borderline patient avoids seeing his case manager every time he suffers a setback at work because his case manager calls it "self-defeating behavior." However, this patient has a separate therapist, who tells him, "I want to see you when things are going badly, not just when they are going well."

Case 4. A 42-year-old schizophrenic patient who can become catatonic at times tells his therapist that the latter is becoming "too pushy" when the therapist urges that he develop a hobby such as studying the plants on the hospital grounds. "It's too much of a burden," says the patient, "and it's not your job to tell me that."

The differing perspectives of case manager and therapist can be helpful in understanding the patient. The patient can at times be oppositional and utilize defensive splitting and rationalization. If an error has been committed in these cases, it would be that the therapist or case manager has assumed the role of critical parent, at least as the patient perceives it. Rather than nurturing the patient with uncritical acceptance, one of the care providers has re-created an atmosphere of parental expectations which has historically proved damaging to the patient. Indeed, we were warned about this type of error by Langs. In all four cases, one might argue, the role of the therapist should be to understand the patient, but not to direct him. This is the role that the therapist in Cases 2 and 3 tried to assume, which the patient in Case 1 needed and the patient in Case 4 asked for. The complexities of supportive therapy are likely to lead to errors, but such difficulties do not constitute a theoretical objection to the therapy itself. 
Failure in the treatment may be catastrophic, as in Case 1, but one cannot assume that another form of treatment would have worked better.

\section{THE QUESTION OF VALUES}

Two key elements in supportive therapy are the real relationship between the therapist and patient and the use of that relationship to modify or control the patient's behavior. Such a situation inevitably raises the question of values. The ethical dilemma is not merely that supportive therapy imparts information. By comparison, one might note that going to a dietician to improve your nutrition does not raise a moral question. You may believe and accept the dietician's advice on trust, and hence the relationship involves an element of faith, but presumably you will not be so influenced by the transference as to lose your independent judgment. For example, you can theoretically cross-check the information you receive from another source. However, it could be argued that it is not morally all right to be directed in your personality by a therapist, because the element of reliance is too great and this makes it too dangerous.

Werman addresses this problem in the context of the therapist's role as auxiliary superego (22). The patient with a weak superego must be told of the destructiveness of his behavior and the need to explore "more benign and substitutive behaviors." Indeed, one is likely to hear more directive statements than that in supportive therapy, such as literal commands to stop using drugs, stop abusing spouse or child, obey the law, or suggestions that the patient needs to spend money more wisely or should go out and round up a new set of friends. The other side of the coin, i.e., the therapist's attempts to weaken an overly punitive superego, does not seem to raise the same ethical concerns.

The conclusion is unavoidable that the therapist is presenting a set of cultural values to the patient, even if they are of the most blatantly legalistic kind and are proffered with the most benign intent. However, how much concern should this raise? Should the therapist be indifferent to whether the patient shows up or takes medicine? Should he be indifferent to the patient's constructive or destructive behaviors? All involve a consideration of what is best for the patient as well as society and a concomitant notion of individual mental health and social propriety.

In general the psychodynamic therapy model attempts to minimize interference with the patient's autonomy to make decisions. The supportive therapy model takes the view that benevolent direction will be in the patient's and/or society's long term interests. Certainly, to the extent that society's interests (e.g., in keeping a potentially dangerous patient from harming others) impinge on the patient's autonomy, the latter is compromised. Certainly, to the extent that the therapist uses direction to keep the patient away from undesirable influences such as drugs, there is impingement on choice. However, both models of autonomy and benevolence have their merits. These have been explicated by Beauchamp and McCullough (32) in the field of medical ethics with the general 
guideline that one chooses the model to fit the patient's knowledge and competence. If we accept Werman's substitutive concept of supportive therapy, we must surely intervene in the patient's life. By contrast, one is reminded of the apocryphal story of the Rogerian therapist who comments dispassionately on his patient's suicidal tendencies and finally observes that the patient has jumped out the window. As therapists, we have already taken our stand in favor of life and certain conceptions of mental health.

In favor of this, one could argue that the patient who accepts supportive therapy has in fact given an implied consent to accept on faith the therapist's influence just as in our earlier example we accepted the dietician's advice. This is generally true, although there are some involuntary patients receiving supportive therapy who may not feel they have the option to reject it.

The ethical issues will require exploration as supportive therapy receives closer scrutiny as a therapeutic modality, but the greatest danger at this time relates to the other ones mentioned earlier, the danger of the therapist misusing the relationship for personal gratification. It is this danger, rather than the likelihood of being brainwashed by the mental health system, which faces the patient whose judgment is impaired. The following examples clarify that concern, although one might imagine that each could be justified in an appropriate context.

1. Telling the patient to leave a religious cult and join an established church, which happens to be the therapist's religion.

2. Arguing exclusively for a monogamous relationship, or specifically telling the patient to get married or divorced, become heterosexual or homosexual.

3. Counseling either for or against an abortion without the patient being the primary decision-maker.

4. Accepting a significant gift from the patient.

5. Accepting unremunerated personal services from the patient such as baby-sitting or errands to the store.

A friend could do all of these things, but it is in this area of values that lies the difference between a friendly therapeutic relationship and an actual friendship. The therapist must adhere to specific objectives of therapy and preserve as much autonomy as the patient is capable of. Friendship follows a different set of rules: friends are able to impose their advice or opinions, and they are allowed to gratify their personal needs through the friendship. We must question the actions above and determine if they have a therapeutic purpose and the therapist is deluding himself or herself about it. Indeed, the first three examples seem to involve an outright imposition of values which is unacceptable. The last two involve the use of the real relationship between patient and therapist, which can be dangerous but might be justified, for example, in the type of therapy derived from Milton Erickson (33). 


\section{THE FUNDAMENTAL DIFFERENCE}

Only now are we in a position to assess whether supportive therapy and psychodynamic therapy are really different in kind or merely different adaptations of techniques to goals. My conclusion is that supportive therapy is primarily a behavioral therapy. To draw an analogy, if you want to call psychodynamic therapy a "watered down" version of psychoanalysis, then you might as well call supportive therapy a watered down version of purely behavioral therapy, such as aversive or desensitization therapy. In some ways this claim is obvious, and in some ways it is not. In Winston's classification, for example, supportive therapy includes much of cognitive and behavioral therapy and certainly such specific techniques as assertiveness training and social skills training.

This is not to imply that these different types of therapy are incompatible. There is presumably only one internal psychic structure, expressed in behavior, to which all therapies are directed. All therapy, including psychoanalysis, is to a degree behavioral, since the patient knows the therapist only through the latter's behavior and the therapist in turn modifies the patient's behavior through various interventions. Beyond this simplistic similarity lies a world of dogmatic dispute. Perhaps it will suffice to recognize that there are polar perspectives, insight-oriented and behavioral, which correspond to what philosophers have called the mentalistic and physicalistic perspectives (34). Psychoanalysis and psychodynamic therapy use primarily mentalistic concepts, whereas the perspective of supportive therapy is primarily behavioral and hence in a language of physical processes. Recognition of this should dispel the notion that supportive therapy is an imprecise and implicitly less effective application of insight-oriented therapy.

The basic assumption of insight-oriented therapy is epitomized in the claim that significant and enduring personality change can be achieved only by psychological insight into hitherto unconscious processes and conflicts. From this follow various corollaries, such as:

1. Cure requires the internal restructuring of this conflict by accessing it as directly as possible.

2. The patient must do the work himself, as an internal sort of mental activity.

3. The therapist can serve only as a guide to the patient's work.

4. Long term, permanent, characterological change is possible only with these methods.

5. Any other therapy must have more limited goals.

This basic assumption and its corollaries are flawed, not because they are wrong, but because they do not tell the whole story. Compare the situation to the question in physics of whether light is a particle or a wave. Both theories of light are true in a macroscopic sense, and on the face of it also appear contradictory. If you had asked a physicist one hundred years ago about the two theories, he 
would have said that one of them must be false, only he did not know which. Today, however, we are better able to explain such macroscopic contradictions on the basis of microscopic quantum mechanics, and we can say that both theories are true in a manner of speaking and the contradiction is only apparent. Similarly, the apparent contradiction between behavioral and insight-oriented methods is probably resolvable to a large extent at a more microscopic level as we understand the relationship of brain, mind, and behavior. Meanwhile we must do our best with both.

I therefore disagree with the assumption, implicit in many sources, that the techniques of supportive therapy are merely the technical modifications of rules of psychodynamic therapy, adapted to the patient's limitations of understanding, ego strength, or crisis situation. Though supportive therapy employs such techniques when they are called for, it also draws upon a repertory of inherently behavioral methods, including the use of modeling, punishment, reward, approval, and praise. It is this behavioral orientation which raises the troublesome ethical problems we have discussed above. However, the specter is not so much Orwell's, but more like Skinner's portrayal of a communal society based on operant conditioning in Walden Two (35).

Seen from the behavioral perspective, one may call supportive therapy a more limited application of insight-oriented therapy. However, one would then have to call insight-oriented therapy a more limited application of supportive therapy. In fact, we could represent them on a spectrum. At one end is self-analysis; at the other is a Skinner box (e.g., a room where a research subject is operantly conditioned). At one end of the spectrum, the therapeutic process is entirely mental; at the other, entirely behavioral. Psychoanalysis and insightoriented therapy reside near the former, while supportive and behavioral therapy reside near the latter. Of course, in practice all therapy involves some overtly observable behavior and some mental activity which is not clearly observable (and may never be). However, we can see that insight-oriented therapy is in no more privileged a position than supportive therapy with respect to its underlying theory. If we accept the parity of the two therapies, then we should abandon any claims that supportive therapy is not psychotherapy (36) and only the patient who draws at the well of his or her personal unconscious is the best patient or doing "real" therapy. Preventing a supportive therapy patient from committing suicide would seem to be a better accomplishment, at least from the behaviorist's perspective, than giving a person insight into his unconscious dynamics while he continues to abuse his spouse.

We must overcome the historical bias of viewing mental accomplishment or insight as more significant than behavioral accomplishment. Under the influence of this bias, for example, the behavioral treatment of phobias was initially scoffed at because it was assumed that symptom substitution would occur. Such an attitude is implicit in Langs' objection to advice-giving discussed above. Yet we must beware whenever theory becomes more important than fact. As one prominent behavioral researcher notes, there is "no solid evidence" that symp- 
tom substitution occurs (37). In supportive therapy, we have found a realm where, due to the patient's ego deficits, behavioral treatments such as advice and support are both necessary and effective.

\section{CONCLUSIONS}

Supportive therapy can be characterized as a set of techniques for egodeficient or ego-stressed patients. We have seen that there are substantial ethical dangers in the delivery of supportive therapy which arise from its behavioral and directive orientation. There is also an underlying theoretical conflict between the behavioral presumptions of supportive therapy and the mentalist assumptions of psychoanalytic therapy which has led practitioners to impugn the purity or methodological correctness of supportive therapy. This conflict is part of the theoretical debate between theories of psychopathology and will not be resolved for some time. Until then, to paraphrase William Jennings Bryan, we should not press the crown of insight down upon the brows of all our patients.

\section{REFERENCES}

1. Nevins A, Commager HS: A Pocket History of the United States. 6th ed. New York, Pocket Books, p 333, 1976

2. Freud S: Lines of advance in psycho-analytic therapy, in Complete Psychological Works, standard ed, vol 5. London, Hogarth Press, 1953-54

3. Wallerstein RS: Psychoanalysis and long-term dynamic psychotherapy, in Review of General Psychiatry, 2nd ed Edited by Goldman HH. Norwalk, Conn, Appleton and Lange, pp 506-514, 1988

4. Bloch S: Supportive psychotherapy, in An Introduction to the Psychotherapies. Edited by Bloch S. New York, Oxford University Press, 1979

5. Werman DS: The Practice of Supportive Psychotherapy. New York, Brunner/ Mazel, 1984

6. Luborsky L: Principles of Psychoanalytic Psychotherapy: A Manual for SupportiveExpressive Treatment. New York, Basic Books, 1984

7. Freud S: Notes upon a case of obsessional neurosis, in Complete Psychological Works, standard ed, vol 10. London, Hogarth Press, 1953-54

8. Kohut H: The two analyses of Mr. Z. Int J Psycho-Analysis 60:3-27, 1979

9. Alexander F, French TM: Psychoanalytic Therapy: Principles and Applications. New York, Ronald Press, 1946

10. Gill MM: Ego psychology and psychotherapy. Psychoanalytic Quart 20:60-71, 1951

11. Alexander TM: Current views on psychotherapy. Psychiatry 16(2):113-122, 1953

12. Goldman GS: Reparative psychotherapy, in Changing Concepts of Psychoanalytic Medicine. Edited by Rado S, Daniels GE. New York, Grune and Stratton, pp 101-113, 1956

13. DeWald PA: Psychotherapy: A Dynamic Approach. New York, Basic Books, 1964

14. Winston A, Pinsker H, McCullough L: A review of supportive psychotherapy. Hosp and Community Psychiatry 37(11):1105-1114, 1986 
15. Buckley P: Supportive psychotherapy: a neglected treatment. Psychiatric Annals 16(9):515-521, 1986

16. Karasu TB: Psychosomatic medicine and psychotherapy. Psychiatric Annals 16(9): 522-525, 1986

17. Pine F: Supportive psychotherapy: a psychoanalytic perspective. Psychiatric Annals 16(9):526-529, 1986

18. Conte HR, Plutchik R: Controlled research in supportive psychotherapy. Psychiatric Annals 16(9):530-533, 1986

19. Ursano RJ, Silberman EK: Individual psychotherapies, in Textbook of Psychiatry. Edited by Talbot JA, Hales RE, Yudowsky SC. Washington, DC, American Psychiatric Press, pp 855-889, 1988

20. Freud S: New introductory lectures on psycho-analysis, in Complete Psychological Works, standard ed, vol 22. London, Hogarth Press, 1953-54

21. Persson G, Alstrom JE: A scale for rating suitability for insight-oriented psychotherapy. Acta Psychiatr Scand 68(2):117-125, 1983

22. Werman DS: Technical aspects of supportive psychotherapy. Psychiatric J of the University of Ottawa 6(3):153-160, 1981

23. Winnicott DW: Hate in the counter-transference. Int J Psychoanalysis 30(2):69-74, 1949

24. Wallace ER: Supportive psychotherapy, in Dynamic Psychiatry in Theory and Practice. Philadelphia, Lea and Febiger, 1983

25. Eissler KR: The effect of the structure of the ego on psychoanalytic technique. J of the American Psychoanalytic Assoc 1(1):104-41, 1953

26. Werman DS: The use of dreams in psychotherapy. Canadian Psychiatric Assoc J 23:153-158, 1978

27. Viederman $M$ : The active dynamic interview and the supportive relationship. Comprehensive Psychiatry 25:147-157, 1984

28. Ermutlu I: Induced dichotomy of personality as a technique in supportive psychotherapy. Psychiatric Forum 7:19-22, 1977

29. Greenson RR: The Technique and Practice of Psychoanalysis, vol. 1. New York, International Universities Press, p 50, 1967

30. Sullivan PR: Learning theories and supportive psychotherapy. Amer J Psychiatry 128(6): 119-122, 1971

31. Langs R: Supportive interventions, chap. 16 of The Technique of Psychoanalytic Psychotherapy, vol. 1. New York, Jason Aronson, 1973

32. Beauchamp TL, McCullough LB: Medical Ethics: The Moral Responsibilities of Physicians. Englewood Cliffs, NJ, Prentice-Hall, 1984

33. Haley J: Uncommon Therapy: The Psychiatric Techniques of Milton H Erickson, MD New York, WW Norton, 1986

34. Shaffer J: Mind-body problem, in Encyclopedia of Philosophy, vol. 5. Edited by Edwards P. New York, Macmillan Publishing, pp 336-346, 1967

35. Skinner BF: Walden Two. New York, Macmillan Co., 1948

36. Crown S: Supportive psychotherapy: a contradiction in terms? British J of Psychiatry 152:266-269, 1988

37. Birk L: Behavior therapy and behavioral psychotherapy, in The New Harvard Guide to Psychiatry. Edited by Nicholi AM. Cambridge, Mass, Harvard University Press, pp 534-562, 1988 